\title{
Vaccination against pneumococcal disease
}

The 1920s and 1930s were productive times for research on pneumococcal disease. It was shown, in experimental animals and in man, that specific capsular polysaccharide could elicit an antibody response, and that the antibody so produced was protective, probably by reason of increased opsonic activity against the homologous strain. All this work culminated in the production of type-specific antisera and, later, in the development of polyvalent pneumococcal vaccines which were licensed for use in the USA just after the end of the second world war. But by this time sulphonamides and penicillin had come into general use and interest in pneumococcal vaccines lapsed until later experience, notably the painstaking work of Robert Austrian, showed that pneumococcal pneumonia and bacteraemia remained an important cause of illness, with a high fatality rate. The apparently insuperable problem of multiple serotypes and type-specific immunity was made manageable when it was found that $82 \%$ of bacteraemic pneumococcal infections in the USA were caused by 14 of the 83 known pneumococcal serotypes. Some new vaccines have been prepared, and one of them (Pneumovax, MSD) containing capsular polysaccharide from these 14 prevalent serotypes, has now been licensed for use in the UK. The vaccine contains $50 \mu \mathrm{g}$ of capsular polysaccharide of each of the 14 serotypes and is unusual in being a chemically defined product without other pharmacologically active components. Antibody responses vary between the types but they are generally satisfactory in adults, and significant protective efficacy has been shown in several populations-notably in South African miners and an adult population in the highlands of Papua New Guinea. ${ }^{1-2}$ Reactions are generally mild-tenderness and induration at the injection site, and fever in some recipients.

The possible role of pneumococcal vaccine in Britain is now under careful scrutiny. For adults, the most obvious target groups would be those for whom influenza vaccination is now recommended, notably those with chronic chest or heart disease, and it is reassuring that antibody response to either pneumococcal or influenza vaccine was not notably reduced by their simultaneous administration. ${ }^{3}$ The chief difficulty in planning such a programme is, oddly enough, lack of up-to-date information about the prevalence of pneumococci and their serotype distribution in exacerbations of bronchitis.
How important is pneumococcal infection in childhood? Pneumococcal pneumonia is now rare in previously healthy children in wealthy countries. Its incidence in poorer communities is largely unknown but, where lung puncture studies have been done, as in west Africa, ${ }^{14}$ the pneumococcus is still shown as the dominant pathogen. Pneumococcal meningitis has its main impact in the first year of life, ranking 3rd in order of frequency in most countries as a cause of bacterial meningitis in childhood. No information is available about the current causes of otitis media in British children but, in countries where myringotomy is practised, Streptococcus pneumoniae accounts for about one-quarter of the cases. Some evidence of protection by pneumococcal vaccine in otitis media of childhood has been obtained in a trial in Finland. ${ }^{4}$ Two groups of subjects are particularly susceptible to pneumococcal infection - those with sickle cell disease, and patients without spleens. Dickerman ${ }^{5}$ has summarised the risks of bacterial sepsis in splenectomised patients, whether by surgery or disease, emphasising that sepsis, especially pneumococcal sepsis, may overcome these patients with catastrophic speed. The risk of pneumococcal infection in other forms of immune suppression varies with the disease. Marshall and Bamforth ${ }^{6}$ point out that these infections are rare in leukaemia, do not seem to affect diabetic children, are now (in contrast with former times) rare in nephrotic syndrome, and do not seem to contribute greatly to the problem of pulmonary infection in cystic fibrosis.

Prevention of a sizeable proportion of otitis media, one important cause of meningitis, some pneumonias, and the commonest cause of lifethreatening sepsis in children with sickle cell disease, or in children without a spleen for some other reason, is an attractive prospect indeed. But several difficulties remain. Antibody response, as with several other bacterial polysaccharide vaccines, is notably poor in children under age 2 ; even in older children the need and timing of revaccination is still uncertain, and revaccination can be accompanied by severe Arthus-like focal reactions. ${ }^{7}$ The poor antibody response in infancy is still a serious disadvantage. Jacobs et al., ${ }^{8}$ in a study of pneumococcal bacteraemia in Chicago, found that $80 \%$ of their patients with pneumococcal meningitis were less than 1-year old. Sickle cell children may gain more since they often develop severe pneumococcal infection after 
infancy, and Ammann et al. ${ }^{9}$ obtained significant protection against pneumococcal infection in sickle cell and other hyposplenic children using an octavalent vaccine. Vaccination does not however, substitute for penicillin prophylaxis if this is indicated, since infection may be caused by a nonvaccine serotype or by a vaccine strain against which the patient has failed to mount an antibody response. Children have died in either of these circumstances. ${ }^{10-11}$ There is still lack of evidence about the responses to vaccination in various forms of immune suppression, so the degree of protection in such groups is therefore uncertain. It seems, for example, that pneumococcal opsonic activity after vaccination is less in splenectomised children than in normal controls. ${ }^{12}$

Finally, the distribution of serotypes in pneumococcal infections, which determines the potential value of a vaccine, differs with location, age group, and type of infection, and needs to be more fully established for infections of childhood in Britain.

The production of a safe purified polyvalent vaccine against pneumococcal disease is a magnificent achievement, but its exact value and role in childhood infection have yet to be established. The population of children with sickle cell disease, those who lack spleens, and those with certain forms of immune suppression stand to gain most at present, and the prospective trial of pneumococcal vaccine for asplenic patients now being mounted should help in defining the indications for its use. A trial to determine if pneumococcal vaccine is effective in preventing serious pneumococcal infections in patients without spleens and to compare its value with that of prophylactic penicillin is in progress.*

The importance of pneumococcal infection in childhood has been abundantly confirmed in recent years. The emergence of penicillin resistance in pneumococci ${ }^{13}$ makes urgent the need to resolve the problems of improving antibody response in infancy and of defining the proper use of this important vaccine.

*Trial is being organised by Dr Richard Mayon-White, Public Health Laboratory, John Radcliffe Hospital, Headington, Oxford OX3 9DU.
References

1 Smit P, Oberholzer D, Hayden-Smith S, Koornhof H J, Hilleman M R. Protective efficacy of pneumococcal polysaccharide vaccine. JAMA 1977, 238: 2613-6.

2 Riley I D, Andrews M, Howard R, et al. Immunisation with a polyvalent pneumococcal vaccine. Lancet 1977; i: 1338-41.

3 Carlson A J, Davidson W L, McLean A A, et al. Pneumococcal vaccine: dose, revaccination, and coadministration with influenza vaccine. Proc Soc Exper Biol Med 1979; 161 : 558-63.

4 Mäkelä P H, Sibakov M, Herva E, et al. Pneumococcal vaccine and otitis media. Lancet 1980 ; ii: $547-51$.

5 Dickerman J D. Splenectomy and sepsis: a warning. Pediatrics 1979; 63: 938-9.

6 Marshall W C, Bamforth J S G. The impact of pneumococcal infections in paediatrics. In: Lambert $\mathbf{H} \mathbf{P}$, Caldwell A D S, eds. Pneumonia and pneumococcal infections. Royal Society of Medicine International Congress and Symposium Series No 27. London: Royal Society of Medicine/Academic Press/Grune \& Stratton, 1980: 103-10.

7 Borgono E, McLean A A, Vella P P, et al. Vaccination and revaccination with polyvalent pneumococcal polysaccharide vaccines in adults and infants. Proc Soc Exper Biol Med 1978; 157 : 148-54.

8 Jacobs N M, Lerdkachornsuk S, Metzger W I. Pneumococcal bacteremia in infants and children: a ten-year experience at the Cook County hospital with special reference to the pneumococcal serotypes isolated. Pediatrics 1979; 64: 296-300.

9 Ammann A J, Addiego J, Wara D W, Lubin B, Smith W B, Mentzer W C. Polyvalent pneumococcalpolysaccharide immunization of patients with sickle cell anemia and patients with splenectomy. $N$ Engl $J$ Med 1977; 297: 897-900.

10 Overturf G D, Field R, Edmonds S. Letter: Death from type 6 pneumococcal septicemia in a vaccinated child with sickle cell disease. $N$ Engl J Med 1979; 300: 143.

11 Appelbaum P C, Shaikh B S, Widome M D, Gordon R A, Austrian R. Letter: Fatal pneumococcal bacteremia in a vaccinated, splenectomized child? N Engl J Med 1979; 300: 203-4.

12 Giebank G S, Quie P G, Schiffman G. Serum opsonic activity and opsonic response to pneumococcal vaccine in splenectomised children. In: Parker M T, ed. Pathogenic streptococci. Chertsey: Reed Books, 1979: 195-6.

13 Aronheim G A, Reich M, Marks M. Penicillin-insensitive pneumococci. Am J Dis Child 1979; 133: 187-91.

14 Silverman M, Stratton D, Diallo A, Egler L J. Diagnosis of acute bacterial pneumonia in Nigerian children. Arch Dis Child 1977; 52: 925-31.

H P LAMBeRT Communicable Diseases Unit, St George's Hospital, Blackshaw Road, London SW17 OQT 